\title{
AVALIAÇÃo dE PROPRIEDADES FísICO-QUímICAS DE CAFÉ ARÁBICA CLASSIFICADOS QUANTO À QUALIDADE DA BEBIDA
}

\author{
Leandro Levate Macedo ${ }^{1}$ \\ Bárbara Zani Agnoletti ${ }^{2}$ \\ Cintia da Silva Araújo ${ }^{3}$ \\ Wallaf Costa Vimercati ${ }^{4}$ \\ Sérgio Henriques Saraiva ${ }^{5}$ \\ Luciano José Quintão Teixeira ${ }^{6}$
}

Resumo: A qualidade da bebida está diretamente relacionada com a composição química dos grãos. É relevante estabelecer uma relação entre a composição química e a qualidade da bebida. O objetivo foi comparar os valores de $\mathrm{pH}$, umidade e teor de sólidos solúveis de cafés arábica (Coffea arabica L.) cru e torrado de diferentes padrões de qualidade da bebida. O café foi submetido a classificação quanto a qualidade da bebida, realizada por provadores treinados. As amostras foram avaliadas quanto ao $\mathrm{pH}$, umidade e teor de sólidos solúveis totais. A torrefação proporcionou algumas alterações na composição dos grãos de café. Para os grãos crus e torrados, o pH apresentou diferenças entre os padrões de qualidade, a umidade não apresentou diferença entre as classificações e o teor de sólidos solúveis totais apresentou-se diferente apenas para a bebida riada cru. Concluiu-se que existem diferenças na composição dos grãos de café relacionadas com a qualidade e tratamento a que estes são submetidos.

Palavras-chave: Café arábica; Qualidade; pH; Umidade; Sólidos solúveis.

\footnotetext{
${ }^{1}$ Programa de pós-graduação em Ciência e Tecnologia de Alimentos/Universidade Federal do Espírito Santo, Brasil. E-mail: leandrolevate@hotmail.com.

2 Programa de pós-graduação em Ciência e Tecnologia de Alimentos/Universidade Federal do Espírito Santo, Brasil. E-mail: bzagnoletti@yahoo.com.br.

3 Programa de pós-graduação em Ciência e Tecnologia de Alimentos/Universidade Federal do Espírito Santo, Brasil. E-mail: araujo.s.cintia@gmail.com.

${ }^{4}$ Programa de pós-graduação em Ciência e Tecnologia de Alimentos/Universidade Federal do Espírito Santo, Brasil. E-mail: wallafcosta@hotmail.com.

5 Professor no Programa de Pós-graduação em Ciência e Tecnologia de Alimentos/Universidade Federal do Espírito Santo, Brasil. E-mail: sergiohsaraiva@gmail.com.

6 Professor no Programa de Pós-graduação em Ciência e Tecnologia de Alimentos/Universidade Federal do Espírito Santo, Brasil. E-mail: luqteixeira@yahoo.com.br.
} 